\title{
UN ACERCAMIENTO AL PATRIMONIO CULTURAL EN ENCLAVES DE CALIDAD VISUAL PAISAJÍSTICA. LAS BATERÍAS MILITARES DE CABO TIÑOSO (CARTAGENA, MURCIA)
}

\author{
M.L. Tudela Serrano \\ M.B. Bernabé Crespo
}

J.Molina Ruiz.

Universidad de Murcia

\section{RESUMEN}

Las Baterías Militares de Cabo Tiñoso son un legado patrimonial inserto en las sierras litorales de Cartagena, en un paisaje poco alterado que hay que valorar por sus características y potencialidades. Con el presente trabajo se quiere dar a conocer y revalorizar este patrimonio militar evaluando y clasificando la calidad visual del paisaje sobre el que se asientan, cuyos principales valores estéticos son el contraste cromático y de texturas entre el mar, suelo, roca y vegetación, a los que se suma la geomorfología acantilada que potencia las vistas. La calidad escénica está modificada en primer plano por la construcción de las Baterías, pero no anulan la calidad visual del paisaje que, a mayor distancia, está libre de actuaciones antrópicas.

Se proponen tres programas con sus líneas de actuación dirigidos a su promoción turística, accesibilidad y protección, y convertirlo en un recurso potencial de desarrollo turístico y local, respetuoso con el medio ambiente y conocedor de los valores culturales.

Palabras clave: Baterías Militares; Paisaje; Patrimonio Natural y Cultural; Calidad Visual.

Recibido: 12 de mayo de 2014

Devuelto para su revisión: 8 de octubre de 2014

Aceptado: 14 de enero de 2015

Departamento de Geografía. Universidad de Murcia. Campus de La Merced. 30001 MURCIA (España). E-mail: mltudela@um.es,miguelborjabc@gmail.com,jmolinar@um.es 


\title{
An approach to cultural heritage in landscape visual quality enclaves. The military batteries of Cape Tiñoso (Cartagena, Murcia)
}

\begin{abstract}
The Military Batteries of Cabo Tiñoso are a heritage legacy located at the coastal mountains of Cartagena, a slightly altered landscape that must be evaluated for their characteristics and potential. The present work aims to discover and enhance this military heritage by evaluating and classifying the visual quality of the landscape on which it is situated and whose main aesthetic values are the color and texture contrast within the sea, soil, rock and vegetation, while geomorphology adds power to the views of cliffs. The scenic quality is modified in the first place by the building of the batteries, but it does not replace the visual quality of the landscape that at a greater distance is free from anthropogenic activities.

Three programs with their policies aimed at the promotion of tourism, accessibility and protection are proposed to make it a potential resource of tourist and local development that respects the environment and is aware of cultural values.
\end{abstract}

Keywords: Military Batteries; Landscape; Natural and Cultural Heritage; Visual Quality.

\section{INTRODUCCIÓN}

Cartagena alberga un importante, rico y extenso patrimonio militar de vigilancia y defensa de su costa, generador de imagen y de revalorización territorial (Castells, 2001), a la vez que es factor y elemento de desarrollo turístico y local. Enclaves de carácter militar, como el Arsenal y los Castillos de Galeras, La Atalaya, Moros y San Julián, o el Hospital de Marina se construyeron en el siglo XVIII, cuando Cartagena pasó a ser capital del Departamento Marítimo del Mediterráneo. En 1912, con la aprobación del Plan de Defensa, se artillaron las baterías de costa: Roldán, Atalaya, Sierra Gorda, Aguilones y Cabo de Agua. Por último, de acuerdo al Plan de Defensa de 1926, se llevó a cabo el despliegue vickers artillando las baterías de costa de Castillitos, Cenizas, Jorel, Aguilones, Parajola, Chapa, Atalayón, Roldán, Conejos y Cabo Negrete (Gómez Vizcaíno, 1997). En 1993 fueron disueltas todas las baterías de costa de Cartagena debido al nuevo planteamiento de la política española de seguridad y defensa.

Todo este conjunto militar se localiza en las sierras litorales de Cartagena, en un enclave que configura un patrimonio y cultura territorial (Martínez, 2006 y Zoido, 2004), que se despliega o plasma en el paisaje (Doctor, 2011) con carácter de legado. La posición geográfica ha configurado su originalidad y paisaje, un paisaje cuya calidad hay que valorar por sus características y potencialidades (Sernatur, 2009), y por su mérito para no ser alterado, o destruido, o para que su esencia se conserve y pueda desempeñar la labor de factor y elemento de desarrollo (Rubio, 2008).

El objetivo del trabajo es dar a conocer y revalorizar este patrimonio militar de la sierra litoral de Cartagena, evaluando y clasificando la calidad visual del paisaje desde las baterías militares de costa de Cabo Tiñoso (Atalayón, Castillitos y Jorel), proponiendo 
unos programas y líneas de actuación dirigidos a su promoción turística, accesibilidad y protección para convertirlo en un recurso potencial de desarrollo turístico y local.

\section{METODOLOGÍA}

Primeramente, se realiza una breve reseña histórica de las baterías que contempla la importancia militar y elementos de interés (armamento y/o estilos arquitectónicos), así como referencias a su protección y propiedad. Seguidamente, se establece la cuenca visual en la que se valora la calidad visual del paisaje en las tres baterías utilizando el método aplicado por USDA Forest Service (1974) y Bureau of Land Management de Estados Unidos (1980) (Tablas 1 y 2) ${ }^{\mathbf{1}}$. Este método indirecto de evaluación separa, analiza y valora, de modo independiente, los factores que conforman el paisaje: «morfología o topografía», «fauna», «vegetación», «formas de agua», «acción antrópica», «fondo escénico», «variabilidad cromática»y «singularidad o rareza». A cada elemento evaluado se le asigna un valor numérico y se determina su calidad visual, alta, media o baja. Por último, se realiza un análisis DAFO (Gómez Orea, 2007) que identifica las fortalezas, oportunidades, debilidades y amenazas que afectan al enclave de las baterías, para así definir programas y líneas de actuación orientados a reducir las debilidades y que éstas no incrementen el riesgo derivado de las amenazas; fortalecer los puntos fuertes y eliminar las amenazas; evitar que las debilidades impidan el aprovechamiento de las oportunidades, y fortalecer los puntos fuertes aprovechando las oportunidades.

Tabla 1

FICHA DE EVALUACIÓN DE CALIDAD DEL PAISAJE

\begin{tabular}{|c|c|c|c|}
\hline $\begin{array}{l}\text { ELEMENTO } \\
\text { VALORADO }\end{array}$ & CALIDAD VISUAL ALTA & CALIDAD VISUAL MEDIA & CALIDAD VISUAL BAJA \\
\hline \multirow[t]{2}{*}{$\begin{array}{l}\text { MORFOLOGÍA O } \\
\text { TOPOGRAFÍA }\end{array}$} & $\begin{array}{l}\text { Pendiente > }>30 \% \text {, estructuras } \\
\text { morfológicas muy modeladas y } \\
\text { de rasgos dominantes y fuertes } \\
\text { contrastes cromáticos. }\end{array}$ & $\begin{array}{l}\text { Pendientes entre } 15 \text { y } 30 \% \text {, } \\
\text { estructuras morfológicas con } \\
\text { modelado suave u ondulado. }\end{array}$ & $\begin{array}{l}\text { Pendiente entre } 0 \text { y } 15 \% \text {, } \\
\text { dominancia del plano horizontal } \\
\text { de visualizaciones, ausencia } \\
\text { de estructuras de contraste o } \\
\text { jerarquía visual. }\end{array}$ \\
\hline & 5 & 3 & 1 \\
\hline \multirow[t]{2}{*}{ FAUNA } & $\begin{array}{l}\text { Presencia de fauna nativa } \\
\text { permanente. Áreas de nidificación, } \\
\text { reproducción y alimentación. }\end{array}$ & $\begin{array}{l}\text { Presencia de fauna nativa } \\
\text { esporádica dentro de la unidad, } \\
\text { sin relevancia visual, presencia } \\
\text { de animales domésticos } \\
\text { (ganado). }\end{array}$ & $\begin{array}{l}\text { No hay evidencia de presencia } \\
\text { de fauna nativa. Sobrepastoreo } \\
\text { o crianza masiva de animales } \\
\text { domésticos. }\end{array}$ \\
\hline & 5 & $\mathbf{3}$ & 1 \\
\hline \multirow[t]{2}{*}{ VEGETACIÓN } & $\begin{array}{l}\text { Presencia de masas vegetales } \\
\text { de alta dominancia visual. Alto } \\
\text { porcentaje de especies nativas, } \\
\text { diversidad de estratos y contrastes } \\
\text { cromáticos. }\end{array}$ & 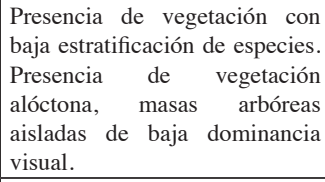 & $\begin{array}{l}\text { Vegetación con un cubrimiento } \\
\text { de suelo }<50 \% \text {. Presencia de } \\
\text { áreas erosionadas con ausencia } \\
\text { de vegetación. Dominancia de } \\
\text { vegetación herbácea, ausencia } \\
\text { de vegetación nativa. }\end{array}$ \\
\hline & 5 & $\mathbf{3}$ & 1 \\
\hline
\end{tabular}

1 Bureau of Land Management de EEUU (1980). Visual Resource Management Program. Div. Of Recreation and Cultural Resource. Washington. Ministerio de Medio Ambiente (2007). Guía para la elaboración de estudios del Medio Físico. $3^{\text {a }}$ edición. Madrid. 


\begin{tabular}{|c|c|c|c|}
\hline \multirow[t]{2}{*}{$\begin{array}{l}\text { FORMAS DE } \\
\text { AGUA }\end{array}$} & $\begin{array}{l}\text { Presencia de cuerpos de agua } \\
\text { con significancia en la estructura } \\
\text { global del paisaje. }\end{array}$ & $\begin{array}{l}\text { Presencia de cuerpos de agua } \\
\text { pero sin jerarquía visual. }\end{array}$ & Ausencia de cuerpos de agua. \\
\hline & 5 & 3 & $\mathbf{0}$ \\
\hline \multirow[t]{2}{*}{$\begin{array}{l}\text { ACCIÓN } \\
\text { ANTRÓPICA }\end{array}$} & $\begin{array}{l}\text { Libre de actuaciones antrópicas } \\
\text { estéticamente no deseadas. }\end{array}$ & $\begin{array}{l}\text { La calidad escénica está } \\
\text { modificada en menor grado por } \\
\text { obras, no atañen a la calidad } \\
\text { visual. }\end{array}$ & $\begin{array}{l}\text { Modificaciones intensas y } \\
\text { extensas que reducen o anulan la } \\
\text { calidad visual del paisaje. }\end{array}$ \\
\hline & 2 & 0 & -2 \\
\hline \multirow[t]{2}{*}{$\begin{array}{l}\text { FONDO } \\
\text { ESCÉNICO }\end{array}$} & $\begin{array}{l}\text { El paisaje circundante potencia } \\
\text { e incrementa el área evaluada. } \\
\text { Presencia de vistas y proyecciones } \\
\text { visuales de alta significación } \\
\text { visual. }\end{array}$ & 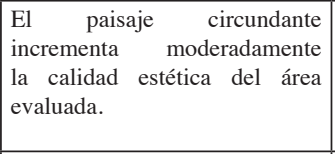 & $\begin{array}{l}\text { El paisaje circundante no } \\
\text { ejerce influencia visual al área } \\
\text { evaluada. }\end{array}$ \\
\hline & \begin{tabular}{|c|}
5 \\
\end{tabular} & \begin{tabular}{|c|}
$\mathbf{3}$ \\
\end{tabular} & $\begin{array}{c}\mathbf{0} \\
\end{array}$ \\
\hline \multirow[t]{2}{*}{$\begin{array}{l}\text { VARIABILIDAD } \\
\text { CROMÁTICA }\end{array}$} & $\begin{array}{l}\text { Combinaciones de color intensas } \\
\text { y variadas. Contraste evidente } \\
\text { entresuelo, vegetación, roca y } \\
\text { agua. }\end{array}$ & $\begin{array}{l}\text { Alguna variedad e intensidad } \\
\text { en color y contraste del suelo, } \\
\text { roca y vegetación, pero no actúa } \\
\text { como elemento dominante. }\end{array}$ & $\begin{array}{l}\text { Muy poca variación de color o } \\
\text { contraste, colores homogéneos o } \\
\text { continuos. }\end{array}$ \\
\hline & \begin{tabular}{|c|}
5 \\
\end{tabular} & \begin{tabular}{|c|}
$\mathbf{3}$ \\
\end{tabular} & 1 \\
\hline \multirow{2}{*}{$\begin{array}{l}\text { SINGULARIDAD } \\
\text { O RAREZA }\end{array}$} & $\begin{array}{l}\text { Paisaje único, con riqueza de } \\
\text { elementos singulares. }\end{array}$ & $\begin{array}{l}\text { Característico, pero similar a } \\
\text { otros de la región. }\end{array}$ & $\begin{array}{l}\text { Paisaje común, inexistencia de } \\
\text { elementos únicos o singulares. }\end{array}$ \\
\hline & \begin{tabular}{|c|}
5 \\
\end{tabular} & \begin{tabular}{|c|}
$\mathbf{3}$ \\
\end{tabular} & 1 \\
\hline TOTAL & & & \\
\hline
\end{tabular}

Tabla 2

FICHA DE CLASIFICACIÓN DE CALIDAD VISUAL DEL PAISAJE

\begin{tabular}{|c|l|l|}
\hline TOTAL & CLASIFICACIÓN & \multicolumn{1}{c|}{ CONNOTACIÓN VISUAL DEL ÁREA } \\
\hline $24-37$ & Calidad Visual alta & $\begin{array}{l}\text { Área con atributos visuales singulares o excepcionales, tanto en su } \\
\text { composición interna como en su organización. Asociada por lo general a áreas } \\
\text { originales. }\end{array}$ \\
\hline $12-23$ & Calidad visual media & Área atractiva visualmente, sin características sobresalientes. \\
\hline$<11$ & Calidad visual baja & $\begin{array}{l}\text { Área carente de elementos singulares o sobresalientes. Por lo general, este } \\
\text { tipo de áreas se encuentran modificadas en su composición o estructura por } \\
\text { actividades antrópicas. }\end{array}$ \\
\hline
\end{tabular}

\section{3. ÁREA DE ESTUDIO}

Las baterías de Atalayón, Castillitos y Jorel ocupan una finca de 233 ha en la franja litoral de la sierra de La Muela, sobre el acantilado de Cabo Tiñoso, en el dominio de la Zona Interna, el Bético «sensu stricto» (IGME, 1972, IGN, 2003) (Fig. 1). Aparece aquí el Alpujárride inferior, con materiales de escasa recristalización y filones-capas de rocas volcánicas, además de una sucesión de calizas y dolomías triásicas que se alzan desde grandes profundidades hasta alcanzar alturas sobre el nivel del mar, comprendidas entre los 20 y más de $200 \mathrm{~m}$. La acción erosiva de las olas sobre el litoral ha configurado un perfil costero, una cornisa en escarpe hacia el sur, de gran valor paisajístico, accidentada y agreste, con acantilados de más de $20 \mathrm{~m}$ de altura, y pequeñas calas abiertas al mar Mediterráneo (Salitrona, Cerrada, Mojarra, del Pozo, de la Avispa...), accesibles únicamente a pie o en embarcación. 


\section{Figura 1 \\ LOCALIZACIÓN DE LA ZONA DE ESTUDIO}

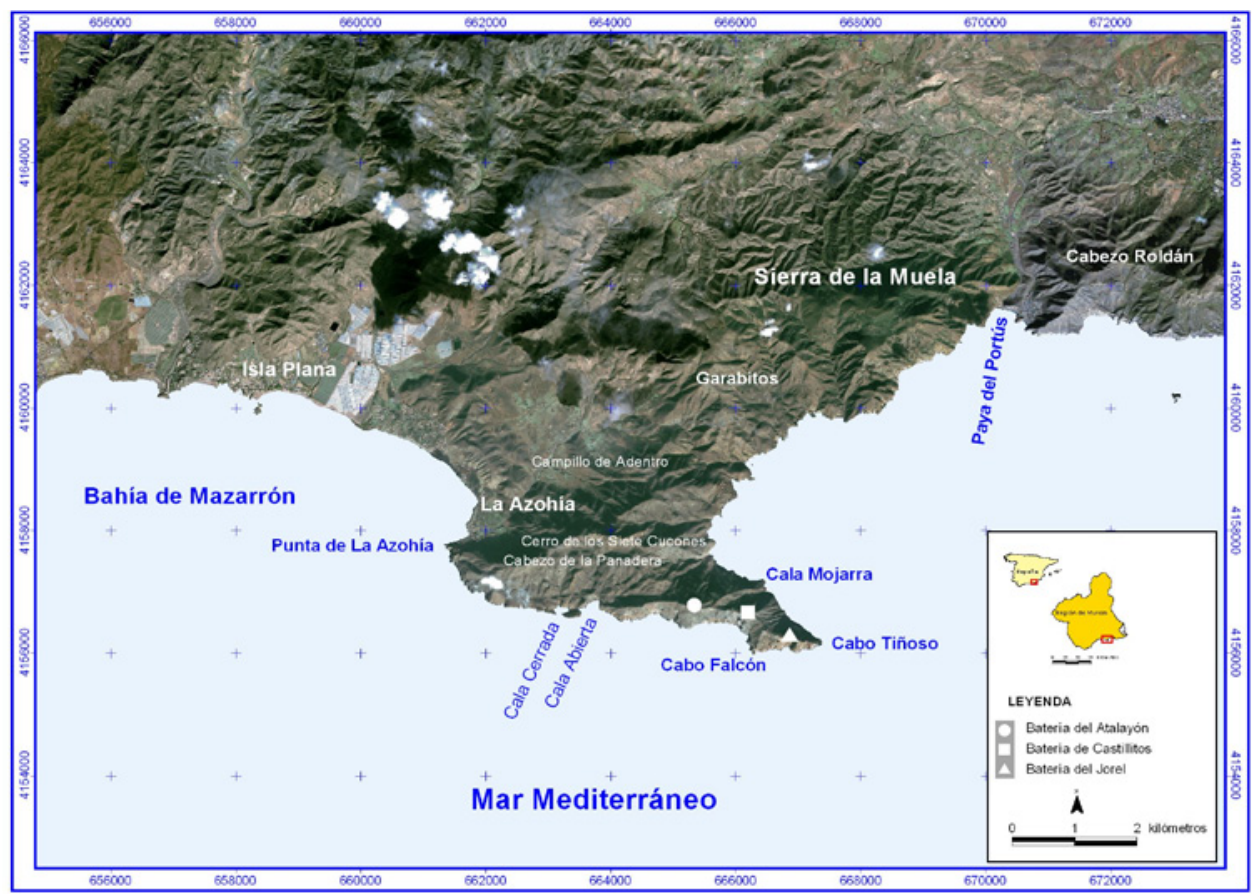

Fuente: Elaboración propia sobre imagen satelital Quickbird 2010.

Destacan las numerosas cuevas submarinas, al pie del acantilado, y el Arco de Cabo Tiñoso, dónde la roca se adentra en el mar en una vertical de $15 \mathrm{~m}$ de profundidad (Figs. 2 y 3 ).

La proximidad del relieve al mar impide el desarrollo de redes de drenaje, presentando pequeñas cuencas por donde discurren cursos de escasa longitud. El clima es mediterráneo de temperaturas suaves en invierno y veranos calurosos, con temperaturas medias diarias elevadas. La pluviometría ofrece registros anuales débiles y es muy irregular, concentradas en pocos días y con la característica mediterránea de la sequía estival (Gil Olcina, 1995). La litología, representada por rocas consolidadas, junto con las fuertes pendientes y las condiciones climáticas, impiden el desarrollo de un suelo en profundidad, siendo los Litosoles los suelos más extendidos (VV.AA, 2000).

Todo el conjunto está incluido en el Espacio Natural Protegido de la Sierra de la Muela, Cabo Tiñoso y Roldán². Es Zona de Especial Protección para las Aves por la presencia del halcón peregrino (Falco peregrinus) y búho real (Bubo bubo); Lugar de Importancia Comunitaria, ES6200015 «La Muela-Cabo Tiñoso», y Zona de Interés Geológico y Geomorfológico, Franja Litoral comprendida entre Punta de La Azohía y el Portús.

2 La Ley 4/1992 de Ordenación y Protección del Territorio y la Ley 7/1995 de la Fauna Silvestre, Caza y Pesca Fluvial reducen el espacio a Cabo Tiñoso y Sierra de la Muela, en 2000 se añade el cabezo de Roldán. 
Figura 2

MORFOLOGÍA DE LA ZONA DE ESTUDIO

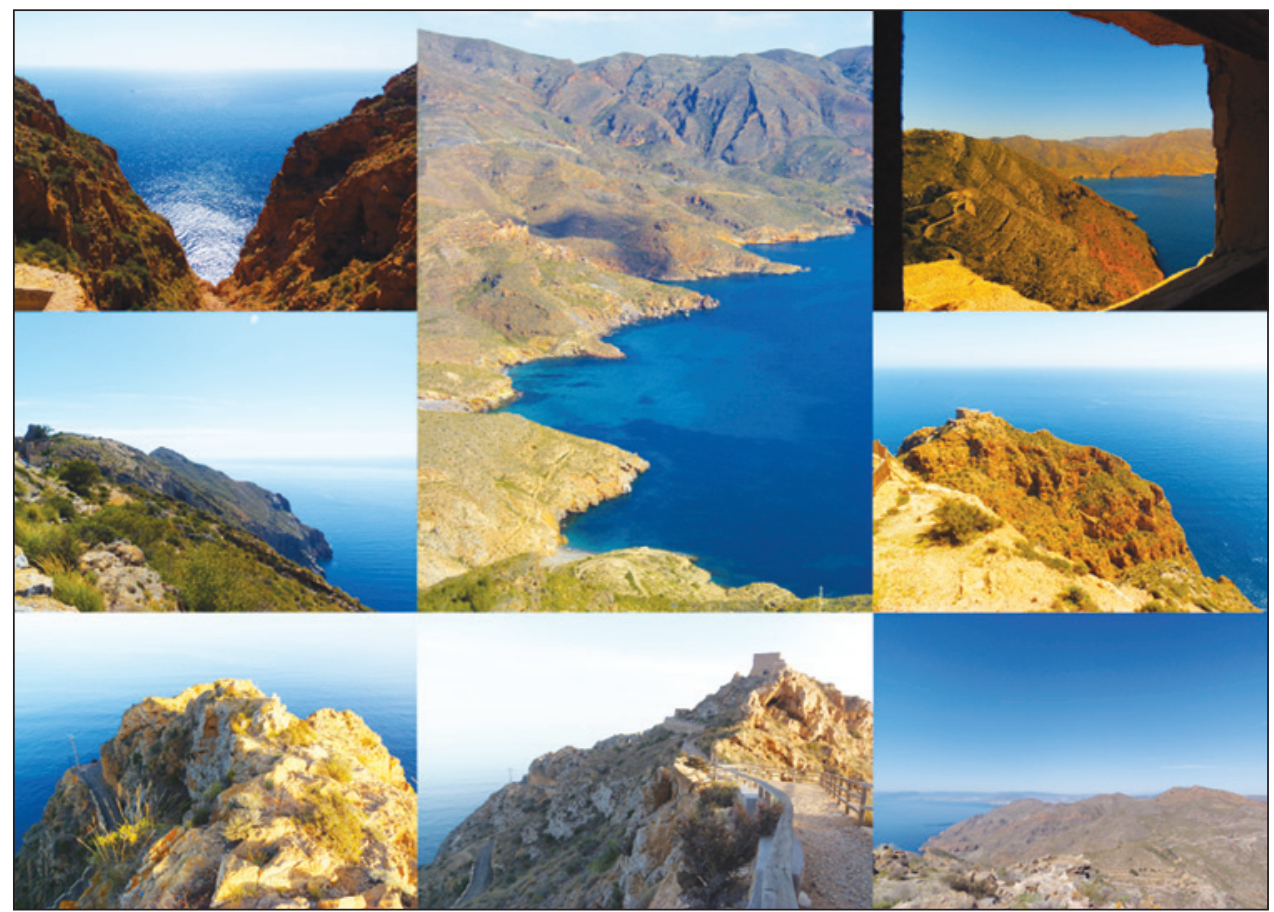

Foto: M.B. Bernabé, 2013.

Figura 3

PERFIL COSTERO DE CABO TIÑOSO (IZQUIERDA Y CENTRO) Y ARCO DE CABO TIÑOSO (DERECHA)

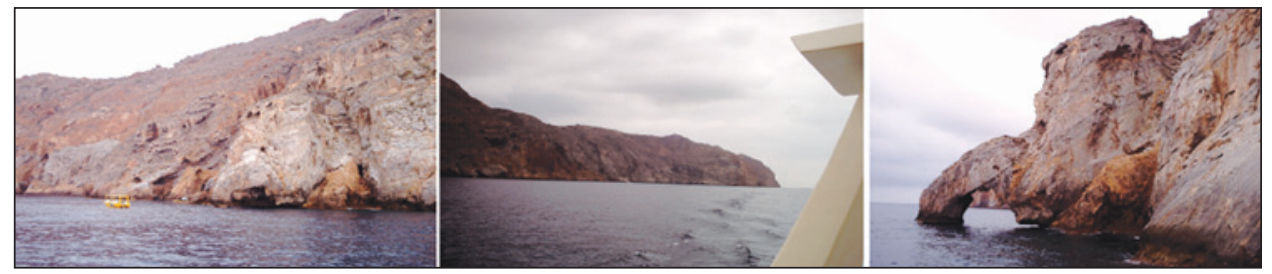

Foto: M.L. Tudela, 2012.

La vegetación predominante es el bosque mediterráneo, combinado con diversos iberoafricanismos, con pinos carrascos, jaras, romeros, acebuches, cornicales, garrigas, palmitos, especies endémicas (Asphodelus fistulosus, varita de San José, Tetraclinis articulata, sabina mora, y Cistus heterophyllus carthaginensis, jara cartagenera). La estepa 
litoral mediterránea también está presente con extensiones de esparto, plantas aromáticas, lavandas y tomillo, y el endemismo Caralluma europaea (chumberillo de lobo). Las formaciones vegetales de los acantilados está caracterizada por especies como Crithmum maritimum, Limonium cossonianum, Lycium intricatum, Asteriscus maritimus, junto con otras propias de ambientes rupícolas como Centaurea saxicola, Lafuentea rotundifolia, Sarcocapnos enneaphylla subsp. saetabensis, Teucrium freynii, Sonchus tenerrimus, Lapiedra martinezii, Sedum dasyphyllum, Satureja obovata subsp. canescens y Rhamnus hispanorum. En las playas y calas, especies como Salsola kali, Eryngium maritimus y Cakile marítima, destacando las escasas poblaciones de Anthemis chrysanta, iberoafricanismo cuya distribución europea se restringe exclusivamente al litoral cartagenero (PORN, 2006). Los fondos marinos concentran una gran riqueza, belleza, representatividad y singularidad, convirtiéndose en uno de los destinos preferidos de submarinismo. En la actualidad está en trámite la declaración de Reserva Marina de Interés Pesquero de Cabo Tiñoso (Cartagena), por su representatividad, singularidad y elevada biodiversidad marina.

Los espacios donde se asientan las baterías se rigen por el Plan General Municipal de Ordenación de Cartagena (PGMO, 1987) y están clasificados, dentro de los Sistemas Generales, como Sistema de servicios públicos de protección y defensa.

Son suelos afectos a Defensa Nacional y de Protección Ambiental y Paisajística (Directrices de Ordenación del Litoral, 2004), que incluyen el ámbito de estudio en el Área funcional «Litoral Suroccidental» (ZEPA Muela-Cabo Tiñoso) incorporando territorios pertenecientes a las subáreas de Cartagena - Mazarrón (La Muela -Tiñoso). Además, han sido declaradas Bien de Interés Cultural en la categoría de Monumento en 1997 por la Disposición Adicional Segunda de la Ley 16/1985, de 25 de Junio del Patrimonio Histórico Español. El PORN de la Sierra de la Muela, Cabo Tiñoso y Roldán establece la Zona de Conservación Prioritaria, siendo clasificadas las baterías militares como Zonas de Uso Público, acogiendo aquellas actividades lúdico-recreativas, de contemplación y educación e interpretación ambiental, encaminadas hacia la conservación de los valores naturales y culturales de la zona. La finca es propiedad del Ministerio de Medio Ambiente y ha sido incorporada al Dominio Público Marítimo Terrestre (D.P.M.T.), a instancias del Programa de adquisición de fincas militares de costa .

\section{RESULTADOS}

El acceso a las baterías se realiza por la carretera Cartagena-Mazarrón (RM E-22), desvío hacia Campillo de Adentro (RM E-23) y continuando la carretera de montaña en ascenso hacia las mismas.

\section{- Batería de Atalayón}

Se construyó entre 1926 y 1933, conforme al Plan de Defensa de 1926, siendo su misión la defensa aérea de las otras dos baterías de Cabo Tiñoso, Castillitos y Jorel, para lo que contaba con cuatro cañones Vickers 105/45 con un alcance de $13 \mathrm{~km}$. En 1952 fue desartillada y, posteriormente, abandonada a requerimiento del Plan NORTE (1994). 
Presenta un estilo de construcción neoclásico. La fachada de los repuestos y depósitos de municiones consta de siete puertas, estando la central coronada con un frontón de estilo jónico y en el pasado, con un escudo mural de la República Las puertas poseen columnas y pilastras jónicas con capiteles de volutas que recuerdan el Templo de Atenea. Se aprecia un arquitrabe acanalado y frisos decorados con gotas y régulas. Actualmente sólo se conservan las barbetas de las piezas, y los pabellones de oficiales y tropa. Además, puestos de mando y dirección de tiro semienterrados para mimetizarse y confundirse con el paisaje, edificios de depósitos de municiones, construcciones para la seguridad como garitas, nidos de ametralladora, etc. (Fig. 4).

\section{Figura 4}

BATERÍA DE ATALAYÓN

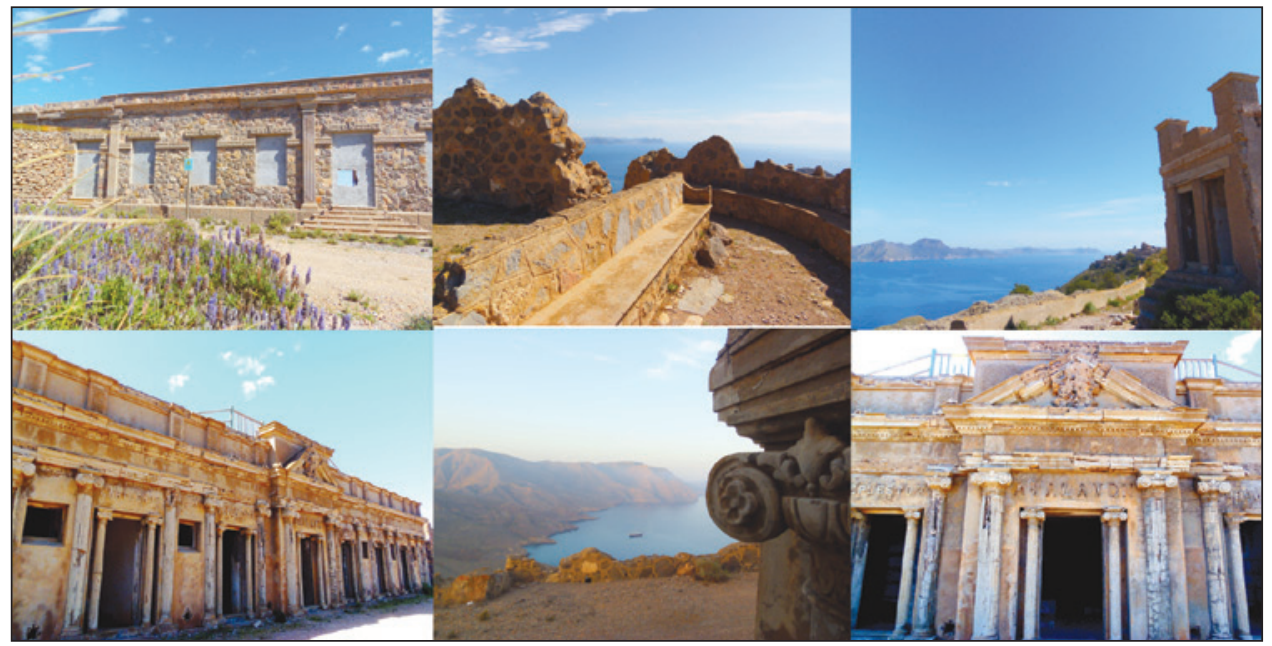

Foto: M.B. Bernabé, 2013.

\section{- Batería de Castillitos}

Se construyó entre 1929 y 1936, conforme al Plan de Defensa de 1926. El 1 de Junio de 1977 realiza su último disparo y estuvo activa hasta 1994, cuando se dejó fuera de servicio debido a las exigencias del Plan NORTE (1994). Contaba con cañones Vickers de $38.1 \mathrm{~cm}$, modelo 1926, con un alcance de 35 kilómetros, y capacidad de lanzamiento de proyectiles de acero de 885 kilos, con 18 kilos de TNT o de alto explosivo con 76 kilos. Cruzaba fuegos con la batería de Cenizas, la batería más lejana y de iguales características, impidiendo el acceso de barcos no deseados. Los fuegos podían alcanzar hasta cabo Cope.

El estilo de la construcción es historicista o ecléctico adaptada al terreno para evitar ser vista desde el mar. Se asemeja a un castillo medieval, con arcos de medio punto y pequeñas torres almenadas semicilíndricas; decoración de arquillo ciego, ventanas abocinadas y paramentos de mampostería de piedra irregular. Las cornisas que coronan los 
edificios poseen bandas lombardas parecidas a las del Románico catalán. En la fachada principal se localiza la dirección de tiro tras la cual se accede a las demás dependencias: sala de máquinas, chillera, depósitos de pólvora, cámara de carga, almacén de repuestos, etc. Desde el pórtico de entrada a los fosos de las piezas se accede a las partes subterráneas de la batería, a una profundidad de doce metros bajo las explanadas de los cañones. Cuenta con varios talleres generales y edificios anexos (Fig. 5).

\section{- Batería de Jorel}

Se construyó entre 1929 y 1933, conforme al Plan de Defensa de 1926. El 10 de Marzo de 1992 realizó sus últimos disparos y desde 1994, debido al Plan NORTE (1994), permanece fuera de servicio. Contaba con cuatro piezas Vickers de 15,24 cm, modelo 1923, de las cuales se mantienen tres. La cuarta pieza se exhibe en el Museo de Artillería de Cartagena. Combina la defensa del eje del puerto de Cartagena con la orientación de su flanco derecho hacia la bahía de Mazarrón, que era accesible a desembarcos.

El estilo de la construcción es neoclásico, aunque más austero que las anteriores. El techo está realizado con forjado de vigas, con paramentos decorados en este estilo. Presenta explanadas para el asentamiento de los cañones y detrás de ellas, los depósitos de municiones aparecen adosados formando un continuo, con sus respectivos montacargas. Contaba, como todas las baterías, con polvorines, chilleras, puestos de mando, etc., y otras construcciones necesarias para la vida y servicios del emplazamiento: alojamientos, oficina, cocina, etc., además de los destinados a la propia seguridad (Fig. 6).

\section{Figura 5 \\ BATERÍA DE CASTILLITOS}

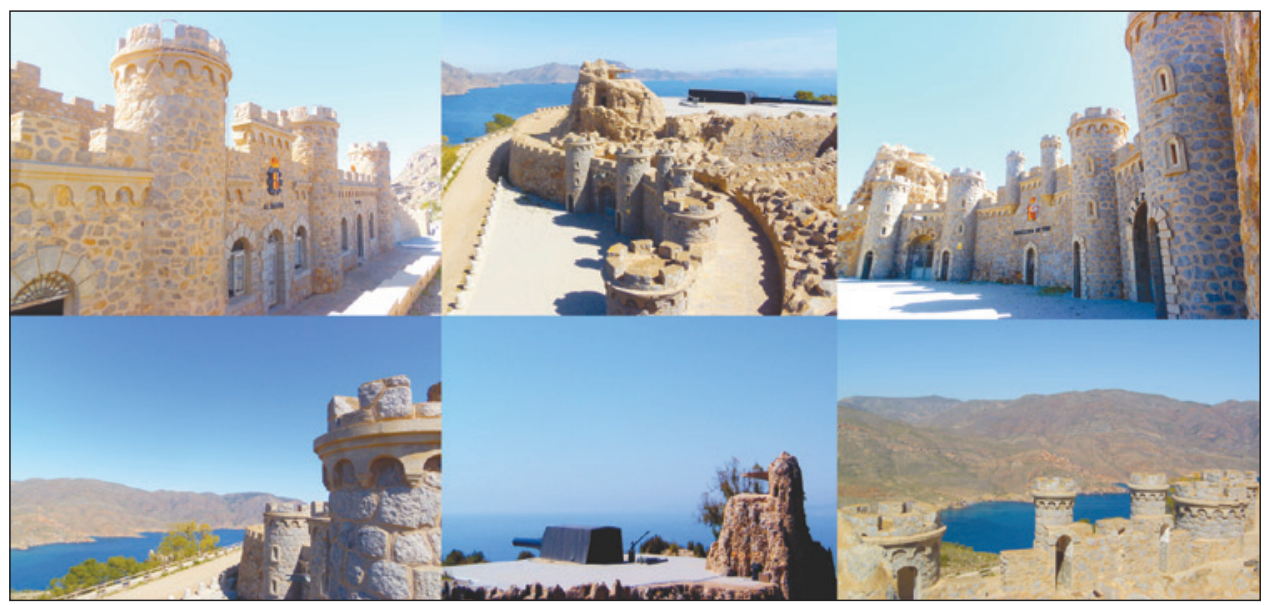

Foto: M.B. Bernabé, 2013. 


\section{Figura 6 \\ BATERÍA DE JOREL}

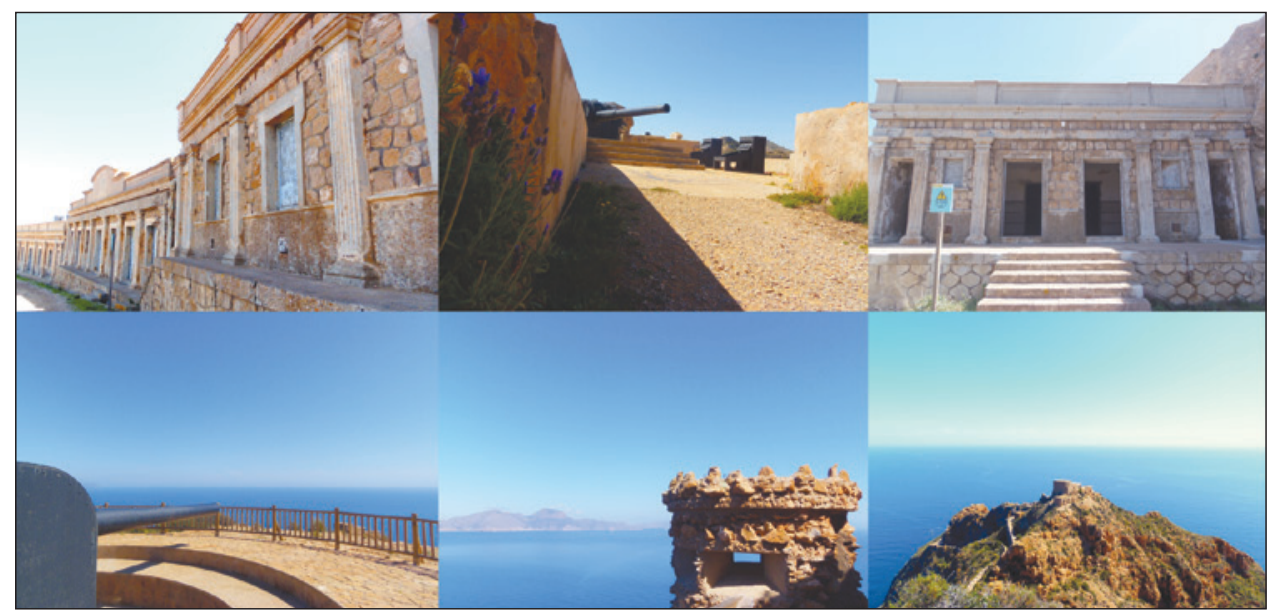

Foto: M.B. Bernabé, 2013.

\subsection{Calidad Visual del Paisaje}

La evaluación de la calidad visual del paisaje se realiza desde la posición en altura de las baterías, lo que permite acceder a una cuenca visual amplia, de estructura y forma redondeada, donde las condiciones atmosféricas juegan un papel fundamental en los rangos de visibilidad del territorio. Las proyecciones visuales, que alcanzan los $2 \mathrm{~km}$, distancia en la que un observador no logra discriminar sobre los atributos del paisaje (Yeomans, 1986), superan los $10 \mathrm{~km}$, distancia recomendada para el cálculo de las cuencas visuales (Bosque et al., 1994), y dónde el tamaño mínimo de atributos del paisaje que el ojo humano puede distinguir es de 2,90 metros (Molina et al., 2001). Este hecho determina que en Cabo Tiñoso, de los tres planos de percepción del paisaje (Escribano et al., 1991), sea el fondo escénico, ocupado por el mar, el que genere la mayor dominancia en las condiciones de visibilidad e incidencia visual, siendo el hito visual mayoritariamente representado en el paisaje.

En el plano próximo y medio, Cabo Tiñoso conforma un paisaje típico de litoral acantilado. Es un paisaje ondulado con presencia de fauna nativa esporádica, sectores erosionados y escasa vegetación. Los principales valores estéticos se deben al contraste cromático y de texturas entre el mar, suelo, roca y vegetación, a los que se suma los derivados de la geomorfología acantilada que potencia e incrementa las vistas. La calidad escénica está modificada en primer plano por las obras de las baterías, pero no anulan la calidad visual del paisaje que, a mayor distancia, está libre de actuaciones antrópicas (Fig. 7).

Hacia el norte, la estructura fallada y plegada es el principal factor del modelado del relieve y el que incrementa la calidad estética del paisaje. Las laderas de la sierra de la Muela y cabezo Roldán, muestra un terreno irregular con barrancos que accidentan el terreno y numerosos derrubios que son consecuencia de los intensos procesos de erosión que tienen lugar sobre las escarpadas laderas. La formación de calas, sobre depósitos 


\section{Figura 7 \\ PLANOS DE PERCEPCIÓN DEL PAISAJE (Foto: M.B. Bernabé, 2013)}

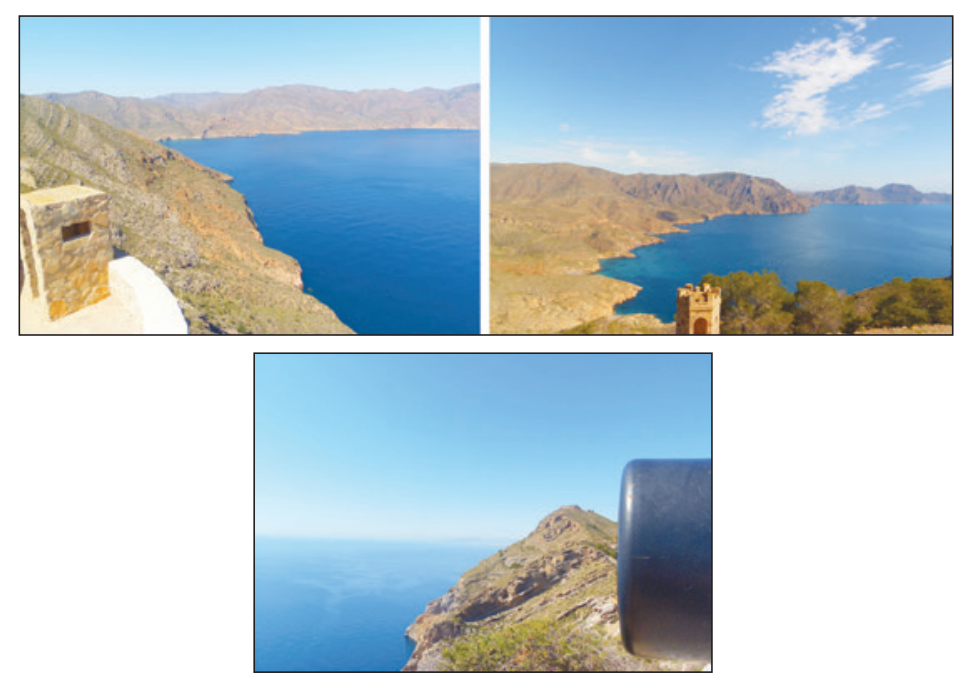

Foto: M.B. Bernabé, 2013.

cuaternarios procedentes de la erosión de las laderas próximas, se debe a la presencia de fallas perpendiculares a la línea de costa, calas Mojarra y Salitrona. El conjunto ofrece una variabilidad cromática alta y las estructuras morfológicas ofrecen como rasgo dominante una pendiente superior al 30\%, laderas colonizadas por espartos, en la solana, y por palmito y pino carrasco, en la umbría. La presencia del mar potencia e incrementa la significancia visual en la estructura global del paisaje (Fig. 8). La calidad visual es alta, en Atalayón y Castillitos, y media en Jorel (Tabla 3).

Al sur, los estratos calizos buzan contra el mar y los acantilados superan los $20 \mathrm{~m}$. Las calas situadas al pie de los mismos son consecuencia de los procesos de erosión que las aguas ejercen sobre los materiales carbonatados, dando lugar también a geoformas de gran valor estético: cuevas, lapiaces, arcos, etc., consecuencia de los procesos de carstificación. El mar ocupa el resto de cuenca visual y en él es frecuente visualizar el paso de grandes arrastreros y el fondeo de buques de carga que se dirigen hacia los puertos próximos de Cartagena, Escombreras y Mazarrón; también, transitan pequeñas embarcaciones pesqueras y de recreo. El mar ocupa la práctica totalidad de la estructura global del paisaje (Fig. 8). La calidad visual es media en Atalayón y Castillitos, y baja en Jorel (Tabla 3).

Hacia el este y el oeste, la presencia de terrenos escarpados desde la sierra de la Muela hasta la sierra de la Fausilla ofrece contrastes cromáticos entre suelo, roca, acantilados, vegetación y mar, pero sin jerarquía visual (Fig. 8). La acción antrópica ocupa un primer plano, el mar un segundo plano y, como último, se visualiza el área de Escombreras, hacia el este, y el litoral mazarronero, su amplia bahía y la llanura litoral, al oeste. Es aquí donde se abre paso un paisaje agrícola de regadío con invernaderos y los núcleos de la Azohía y San Ginés. La calidad visual es media en Atalayón, Castillitos y Jorel (Tabla 3). 
Figura 8

\section{CUENCA VISUAL DESDE LAS BATERÍAS}

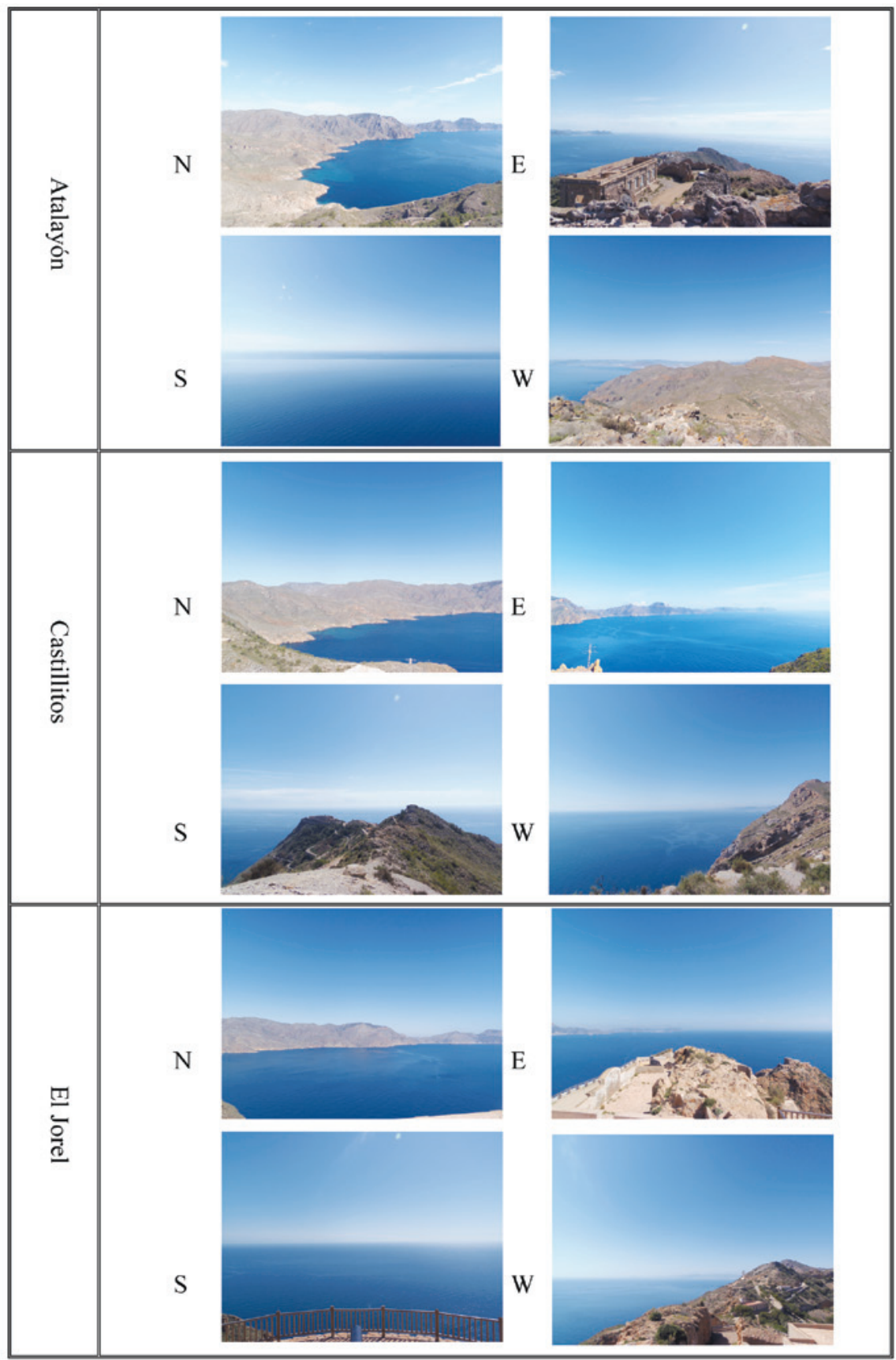


Tabla 3

CLASIFICACIÓN DE LA CALIDAD VISUAL DEL PAISAJE

Batería del Atalayón. Coordenadas 37 32' 29.05" N $1^{\circ} 07^{\circ} 48.83$ ” W; elevación 348 m.

Batería de Castillitos. Coordenadas $37^{\circ} 32$ ' 24.88" N $1^{\circ} 07$ ' 13.17" W; elevación $252 \mathrm{~m}$.

Batería del Jorel. Coordenadas $37^{\circ} 32^{\prime} 11.71$ ” N 1º6' 45.66” W; elevación $170 \mathrm{~m}$.

\begin{tabular}{c|cccccc}
\hline CUENCA & \multicolumn{6}{c}{ CALIDAD VISUAL DEL PAISAJE (C.V.) } \\
\cline { 2 - 4 } & ATALÁN & C.V. & CASTILLITOS & C.V. & JOREL & C.V. \\
NORTE & 25 & Alta & 25 & Alta & 23 & Media \\
SUR & 12 & Media & 19 & Media & 10 & Baja \\
ESTE & 19 & Media & 23 & Media & 19 & Media \\
OESTE & 19 & Media & 23 & Media & 17 & Media \\
\hline
\end{tabular}

\subsection{Análisis DAFO}

Se realiza el análisis DAFO cumplimentando sus dos matrices: la matriz DAFO (Tabla 4), con objeto de identificar las fortalezas, las debilidades, las oportunidades y las amenazadas que se ciernen en el patrimonio natural y cultural sobre el que se localizan las baterías; y, la matriz de Confrontación (Tabla 5) de la que deriva la propuesta de programas y sus líneas de actuación.

Tabla 4

\section{MATRIZ DAFO}

\begin{tabular}{|c|c|c|c|}
\hline FORTALEZAS & DEBILIDADES & OPORTUNIDADES & AMENAZAS \\
\hline $\begin{array}{l}\text { F1. Interés de la po- } \\
\text { blación por conocer } \\
\text { los valores culturales } \\
\text { del territorio. }\end{array}$ & $\begin{array}{l}\text { D1. Mal estado de } \\
\text { conservación de los } \\
\text { accesos. }\end{array}$ & $\begin{array}{l}\text { O1. Existencia de un Plan } \\
\text { Director Regional de Sen- } \\
\text { derismo Región de Mur- } \\
\text { cia y de una Red de Itine- } \\
\text { rarios Ecoturísticos. }\end{array}$ & $\begin{array}{l}\text { A1. Escasez de capi- } \\
\text { tales y de inversión } \\
\text { para mejora de insta- } \\
\text { laciones y realización } \\
\text { de actividades cientí- } \\
\text { fico-culturales. }\end{array}$ \\
\hline $\begin{array}{l}\text { F2. Gran valor histó- } \\
\text { rico, arquitectónico y } \\
\text { militar. }\end{array}$ & $\begin{array}{l}\text { D2. Escasa protección } \\
\text { ante expolios, lo que } \\
\text { conlleva su degrada- } \\
\text { ción. }\end{array}$ & $\begin{array}{l}\text { O2. Interés por parte del } \\
\text { Ministerio de Medio Am- } \\
\text { biente en la conservación } \\
\text { y gestión del patrimonio } \\
\text { militar. }\end{array}$ & $\begin{array}{l}\text { A2. Escasa participa- } \\
\text { ción de la administra- } \\
\text { ción. }\end{array}$ \\
\hline $\begin{array}{l}\text { F3. Presencia de Lu- } \\
\text { gares de Importancia } \\
\text { Geológica y de alto } \\
\text { valor paisajístico. }\end{array}$ & $\begin{array}{l}\text { D3. Falta de progra- } \\
\text { mación en centros } \\
\text { educativos para su } \\
\text { puesta en valor. }\end{array}$ & $\begin{array}{l}\text { O3. Pertenencia al Espa- } \\
\text { cio Natural Protegido de } \\
\text { Sierra de la Muela, Cabo } \\
\text { Tiñoso y Roldán. }\end{array}$ & $\begin{array}{l}\text { A3. Competitividad } \\
\text { con otros espacios } \\
\text { turísticos en la zona } \\
\text { más accesibles y ren- } \\
\text { tables. }\end{array}$ \\
\hline
\end{tabular}




\begin{tabular}{|c|c|c|c|}
\hline $\begin{array}{l}\text { F4. Actividades orga- } \\
\text { nizadas por federacio- } \\
\text { nes deportivas, grupos } \\
\text { de scout y otros gru- } \\
\text { pos }\end{array}$ & $\begin{array}{l}\text { D4. Accesibilidad li- } \\
\text { mitada para determi- } \\
\text { nados grupos de edad } \\
\text { y con necesidades es- } \\
\text { peciales. }\end{array}$ & $\begin{array}{l}\text { O4. Proximidad a los nú- } \\
\text { cleos turísticos de Maza- } \\
\text { rrón, Mar Menor y Carta- } \\
\text { gena. }\end{array}$ & $\begin{array}{l}\text { A4. Excesiva afluen- } \\
\text { cia turística incontro- } \\
\text { lada que deteriore o } \\
\text { transforme el patri- } \\
\text { monio militar. }\end{array}$ \\
\hline $\begin{array}{l}\text { F5. Espacios naturales } \\
\text { incluidos la Red Natu- } \\
\text { ra } 2000 .\end{array}$ & \multirow[t]{3}{*}{$\begin{array}{l}\text { D5. Aprovechamien- } \\
\text { to turístico escaso por } \\
\text { desconocimiento de su } \\
\text { existencia. }\end{array}$} & $\begin{array}{l}\text { O5. Realización de even- } \\
\text { tos deportivos ligados a la } \\
\text { Ruta de las Fortalezas. }\end{array}$ & $\begin{array}{l}\text { A5. Estacionalidad } \\
\text { del turismo. }\end{array}$ \\
\hline $\begin{array}{l}\text { F6. Zona poco alte- } \\
\text { rada por la presencia } \\
\text { humana. }\end{array}$ & & $\begin{array}{l}\text { O6. Apertura del Puerto } \\
\text { de Cartagena al turismo } \\
\text { de cruceros. }\end{array}$ & \multirow{2}{*}{$\begin{array}{l}\text { A6. Preferencia de los } \\
\text { turistas por destinos } \\
\text { más comerciales en } \\
\text { otros países y/o re- } \\
\text { giones ya insertos en } \\
\text { programaciones turís- } \\
\text { ticas. }\end{array}$} \\
\hline $\begin{array}{l}\text { F7. Climatología sua- } \\
\text { ve con buenas condi- } \\
\text { ciones meteorológi- } \\
\text { cas. }\end{array}$ & & $\begin{array}{l}\text { O7. Elevada calidad pai- } \\
\text { sajística para dar a cono- } \\
\text { cer. }\end{array}$ & \\
\hline
\end{tabular}

Tabla 5

MATRIZ DE CONFRONTACIÓN

\begin{tabular}{|c|c|c|c|c|c|c|c|c|c|c|c|c|c|c|c|}
\hline & & \multicolumn{7}{|c|}{ OPORTUNIDADES } & \multicolumn{6}{|c|}{ AMENAZAS } & \multirow[b]{2}{*}{ TOTAL } \\
\hline & & O1 & $\mathrm{O} 2$ & $\mathbf{O 3}$ & O4 & O5 & O6 & O7 & A1 & A2 & A3 & A4 & A5 & A6 & \\
\hline \multirow{7}{*}{ 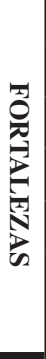 } & F1 & + & + & + & + & + & + & + & + & + & - & - & $=$ & - & 10 \\
\hline & F2 & + & + & + & + & + & + & + & - & - & - & - & $=$ & $=$ & 11 \\
\hline & F3 & + & + & + & + & + & + & + & - & - & + & - & $=$ & $=$ & 10 \\
\hline & F4 & + & + & + & + & + & $=$ & + & - & - & - & + & $=$ & $=$ & 9 \\
\hline & F5 & + & + & + & + & + & + & + & + & + & + & + & - & - & 9 \\
\hline & F6 & + & + & + & + & + & + & + & $=$ & $=$ & + & + & - & - & 9 \\
\hline & F7 & $=$ & $=$ & $=$ & + & + & + & + & $=$ & $=$ & $=$ & $=$ & $=$ & $=$ & 4 \\
\hline \multirow{5}{*}{ 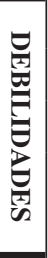 } & D1 & - & - & - & - & - & - & - & + & + & + & + & $=$ & $=$ & 11 \\
\hline & D2 & - & - & - & - & - & - & - & + & + & $=$ & + & $=$ & $=$ & 10 \\
\hline & D3 & - & - & - & - & - & $=$ & $=$ & + & + & + & $=$ & $=$ & $=$ & 8 \\
\hline & D4 & - & - & - & - & - & $=$ & $=$ & + & + & + & - & $=$ & + & 9 \\
\hline & D5 & - & $=$ & - & - & - & - & - & + & + & + & - & $=$ & $=$ & 9 \\
\hline & TOTAL & 1 & 2 & 1 & 2 & 2 & 3 & 4 & 4 & 4 & 4 & $\mathbf{0}$ & -2 & -2 & \\
\hline
\end{tabular}

Según se desprende de este análisis, los programas y sus líneas de actuación van encaminados a consolidar y potenciar las fortalezas, sobre todo aquellas surgidas de la riqueza natural del entorno y del gran valor histórico, arquitectónico y militar de las bate- 
rías, aprovechando las oportunidades que ofrecen la proximidad de destinos turísticos ya consolidados, La Manga, Mar Menor y Mazarrón, y la iniciativa de la Región de Murcia referente a la implantación de una Red de Itinerarios Ecoturísticos definida por la Red Verde Europea para el Área del Mediterráneo Occidental (REVERMED)³.

Los problemas que surgen por las debilidades se incrementan con las amenazas, sobre todo aquellas referentes a la falta de financiación por parte de la Administración para la inversión en mejora de accesos, protección de las baterías e información para su puesta en valor como destino turístico. Se debe hacer hincapié en aprovechar la benignidad anual del clima para romper la estacionalidad del turismo regional y poder competir con otros destinos turísticos. Los programas y actuaciones que se planteen irán dirigidos a promocionar el espacio y convertirlo en un recurso potencial de desarrollo turístico y local, respetuoso con el medio ambiente y conocedor de los valores culturales.

\subsection{Programas y Líneas de Actuación}

\section{- Programa de Promoción Turística}

Tiene como objetivo dar a conocer el patrimonio militar que encierran las baterías como producto turístico natural y cultural. Las fortalezas se unen a las oportunidades para superar las amenazas. Se desarrolla en las siguientes líneas de actuación:

$\checkmark$ Elaborar materiales promocionales en soporte papel y virtual, incluso la elaboración de audiovisuales promocionales, para colgar en sitios web, en los que ensalzar los valores culturales y naturales, poco alterados por la acción antrópica.

$\checkmark$ Diseñar jornadas turísticas y de ocio en las baterías, aprovechando la proximidad de núcleos turísticos consolidados, y la reciente implantación de la terminal de cruceros en Cartagena. Un destino turístico ambiental y patrimonial, tanto para su realización a pie, como en barco, aprovechando las atractivas particularidades paisajísticas del perfil costero.

$\checkmark$ Promover la creación de un espacio temático patrimonial que convierta las baterías militares en un escenario donde el visitante haga un recorrido por el tiempo y sea protagonista de toda una experiencia cultural.

$\checkmark$ Establecer un Programa de Cooperación, Promoción y Difusión Cultural en el exterior determinando actuaciones relacionadas con el Patrimonio Histórico y Cultural de las baterías.

$\checkmark$ Diseñar un itinerario ecoturístico que quede integrado en la red RISERM regional, red que también define la Red Verde Europea para el Área del Mediterráneo Occidental (REVERMED), y sus conexiones con las comunidades autónomas limítrofes.

3 REVERMED es un proyecto europeo aprobado por el Comité de Programación INTERREG III B Medoc, inspirado en la Declaración de Lile (2001) que pretende complementar la Red Verde iniciada en el Noroeste de Europa (Proyecto REVERMED AMNO INERRREG II C. Estaba integrado por 32 socios de España, Portugal, Francia e Italia, y se configuró mediante un gran esquema director que da coherencia y garantiza la continuidad de la red entre regiones y países. 
- Programa de accesibilidad

Destinado a cubrir las necesidades del usuario turístico. Las actuaciones van orientadas a mejorar el acceso de los visitantes, tanto en infraestructuras viarias como en la eliminación de barreras arquitectónicas para personas con movilidad reducida, haciendo accesible el espacio para todos. Se reducen las debilidades aprovechando las oportunidades, apoyándose en las fortalezas y mitigando las amenazas. Se desarrolla en las siguientes líneas de actuación:

$\checkmark$ Mejorar los aspectos técnicos de acceso a las baterías para garantizar su practicabilidad, incluyendo criterios de accesibilidad para las personas con movilidad reducida, disponiendo de los oportunos elementos de seguridad y balizamiento, y definiendo usos compatibles y complementarios.

$\checkmark$ Implantar un sistema de señalización gráfica, informativa, direccional, interpretativa y normativa a lo largo de todo un recorrido por las baterías.

$\checkmark$ Mejorar el área de aparcamiento y dimensionarla a la demanda y exigencias del entorno, así como disponer de una zona de descanso integrada escénicamente.

$\checkmark$ Implantar un sistema de gestión de residuos (separación selectiva y servicio de recogida).

$\checkmark$ Habilitar un centro de visitantes e interpretación que actúe como punto de referencia.

$\checkmark$ Elaborar un Programa de Voluntariado Ambiental para la conservación del entorno y la sostenibilidad, a instancias de la administración ambiental y en coordinación con diversas organizaciones sociales.

- Programa de protección de las baterías militares y su entorno

Su finalidad es proteger el espacio natural y cultural, extendiendo la conciencia ambiental, a través del conocimiento. Se potencia eliminar las debilidades y minimizar las amenazas aprovechando las oportunidades. Se desarrolla en las siguientes líneas de actuación:

$\checkmark$ Configurar un programa de actividades divulgativas y de educación ambiental, en el que poner en valor el respeto medioambiental y la práctica de buenas conductas para llevarlo a cabo.

$\checkmark$ Dotar de un sistema de vigilancia y seguridad que prevenga, persiga y garantice los altercados y delitos contra el patrimonio natural y cultural de las baterías.

$\checkmark$ Velar por el cumplimiento de la Normativa de Protección actual y dotar al espacio de una mayor protección jurídica.

$\checkmark$ Poner en práctica metodologías e indicadores para determinar la capacidad de acogida y de carga de los distintos usos y actividades que se contemplen.

$\checkmark$ Solicitar colaboración con centros de investigación, públicos y/o privados, para la realización de estudios de investigación de índole natural y cultural.

$\checkmark$ Proceder a una gestión competente de las ayudas y subvenciones procedentes de la Unión Europea y del ámbito estatal y regional, con la finalidad de proteger y rehabilitar el entorno y elementos patrimoniales de las baterías.

$\checkmark$ Crear una red de voluntariado para una colaboración libre y desinteresada en el mantenimiento y mejora de las baterías militares y de su entorno. 


\section{CONCLUSIONES}

Las baterías militares de Cabo Tiñoso son un legado patrimonial inserto en las sierras litorales de Cartagena, en un paisaje cuyos principales valores estéticos son el contraste cromático y de texturas entre el mar, suelo, roca y vegetación. A la estructura fallada y plegada del relieve y con numerosos barrancos que accidentan el terreno, se suma una geomorfología acantilada que da lugar a geoformas de gran valor estético: cuevas, lapiaces, arcos, etc. Si bien, la calidad escénica está modificada en primer plano por la construcción de las baterías, éstas no anulan la calidad visual del paisaje que, a mayor distancia, está libre de actuaciones antrópicas, siendo el mar quien potencia e incrementa la significancia visual en la estructura global del paisaje:

- La calidad visual es alta, en Atalayón y Castillitos, y media en Jorel, hacia el norte.

- La calidad visual es media en Atalayón y Castillitos, y baja en Jorel, hacia el sur.

- La calidad visual es media en Atalayón, Castillitos y Jorel, hacia el este y el oeste.

$\mathrm{Su}$ fortaleza reside en el alto valor natural y cultural del conjunto, también en una climatología benigna y la escasa presencia humana. La debilidad es la deficitaria accesibilidad en infraestructuras viarias y con barreras arquitectónicas; el mal estado de conservación de las baterías y su escasa difusión educativa son también debilidades a mitigar. El Espacio Natural Protegido de Sierra de la Muela, Cabo Tiñoso y Roldán, y los núcleos turísticos consolidados de La Manga, Mar Menor y Mazarrón, son oportunidades para beneficiar al desarrollo turístico y local. La amenaza más importante es la ausencia de capitales para llevar a cabo una programación eficiente, siendo la descontrolada afluencia de visitantes en un entorno sin los necesarios servicios la que puede hacer peligrar la supervivencia de las baterías como enclaves diferenciados, actualmente muy deteriorados. Los programas destinados a aprovechar las oportunidades, mitigar el riesgo derivado de las amenazas y fortalecer, superando las debilidades, son tres:

- Promoción turística, destinado a promocionar el patrimonio militar como producto turístico, natural y cultural.

- Accesibilidad, tendente a cubrir las deficiencias para el usuario potencial.

- Protección de las baterías y su entorno, que extiende la conciencia ambiental a través del conocimiento.

Por último, las baterías de Cabo Tiñoso son un patrimonio militar, asentado en un paisaje con gran visibilidad e incidencia visual, que puede convertirse en un recurso potencial de desarrollo turístico y local, conocedor de sus valores naturales y culturales.

\section{BIBLIOGRAFÍA}

BOSQUE, J., ESCOBAR, F.J., GARCÍA, E. y SALADO, M.J. (1994): Sistemas de Información Geográfica: Prácticas con PC ARC/INFO e IDRISI. (Ed.) RA-MA. Madrid, $478 \mathrm{pp}$. 
CASTELLS, M. (2001): «Reencontrar el Patrimonio. Estrategias de desarrollo territorial a partir de la Interpretación», Ponencia en Congreso Virtual Perspectivas del Turismo Cultural. http://www.naya.org.ar/turismo_cultural/congreso/ponencias/margalida_castells2.htm

DIRECTRICES Y PLAN DE ORDENACIÓN TERRITORIAL DEL LITORAL DE LA REGIÓN DE MURCIA (2004). Consejería de Turismo y Ordenación del Territorio. Región de Murcia.

DOCTOR, A. (2011). «El itinerario como herramienta para la puesta en valor turístico del patrimonio territorial». Cuadernos de Turismo, no 27, pp. 273-289.

ESCRIBANO, M., DE FRUTOS, M., IGLESIAS, E., MATAIX, C. y TORRECILLA, I. (1991). El Paisaje. Unidades Temáticas Ambientales. Ministerio de Obras Públicas y Transporte. Madrid.

GIL OLCINA, A. (1995): «Rasgos específicos del Sureste Peninsular», Paralelo $37^{\circ}$. Revista de Estudios Geográficos, n 17, pp. 69-79.

GÓMEZ OREA, D. (2007): Ordenación Territorial. Editorial Mundi-Prensa Libros S.A. Madrid, $766 \mathrm{pp}$.

GÓMEZ VIZCAINO, A. (1997). Castillos y fortalezas de Cartagena. Ed. Aforca. 127 p. IGME (1972). Mapa Geológico de España, Serie Magna 50. Hojas 977 Cartagena y 978 Llano del Beal.

IGN (2003). Mapa Topográfico Nacional, escala 1/25.000, hoja 977-III La Azohía.

LEY 16/1985, de 25 de Junio del Patrimonio Histórico Español. Publicado en BOE de 29 de Junio de 1985 .

MARTÍNEZ, C. (2006): El Patrimonio Cultural: los nuevos valores, tipos, finalidades y formas de organización. Tesis Doctoral, Universidad de Granada.

MOLINA, J., TUDELA, M.L., CANO, P. y BUENO, J.M. (2001): «Minimización del impacto paisajístico en la actividad minera a cielo abierto. Demostración teórica y práctica de los costes de restauración». Papeles de Geografía, no 33, pp. 123-131.

PGMO (1987). Plan General Municipal de Ordenación. Ayuntamiento de Cartagena 166 p. PORN (2006): Plan de Ordenación de los Recursos Naturales del Espacio Protegido de Sierra de la Muela, Cabo Tiñoso y Roldán. Dirección General del Medio Natural, Consejería de Industria y Medio Ambiente. Comunidad Autónoma de la Región de Murcia.

PLAN NORTE (1994): Plan de Nueva Organización del Ejército. OM 84/1994, BOE 213 modificada por OM 146/1995, BOD 288.

RUBIO, P. (2008): «Desarrollo local y patrimonio cultural. El Parque Cultural de Albarracín», Geographicalia, n ${ }^{\circ}$ pp. 21-48.

SERNATUR (SERVICIO NACIONAL DE TURISMO ) (2009). Turismo y Paisaje. Una aproximación al Sistema de Evaluación de Impacto Ambiental. Servicio Nacional de Turismo. Gobierno de Chile, Santiago (Chile), 130 pp.

VV.AA. (2000): Mapa digital de suelos de la Región de Murcia. Consejería de Agricultura, Agua y Medio Ambiente. Comunidad Autónoma de la Región de Murcia, 78 pp.

YEOMANS, W.C. (1986). Visual Impact Assessment: Changes in natural an rural environment. John Wiley and sons, New York.

ZOIDO, F. (2004): «El paisaje. Patrimonio público y recurso para la mejora de la democracia», PH, Boletín del Instituto Andaluz de Patrimonio Histórico, n 50, pp. 66-73. 